\title{
BMJ Open Disparities in HIV/STI burden and care coverage among men and transgender persons who have sex with men in Nairobi, Kenya: a cross-sectional study
}

\author{
Adrian D Smith (D) , ${ }^{1}$ Elizabeth Fearon, ${ }^{2}$ Rhoda Kabuti, ${ }^{3}$ Erastus Irungu, ${ }^{3}$ \\ Mary Kungu, ${ }^{3}$ Hellen Babu, ${ }^{3}$ Chrispo Nyabuto, ${ }^{3}$ Peter Muthoga, ${ }^{4}$ \\ Peter Weatherburn, ${ }^{5}$ Adam Bourne, ${ }^{6}$ Joshua Kimani ${ }^{7,8}$
}

To cite: Smith $A D$, Fearon $E$, Kabuti $\mathrm{R}$, et al. Disparities in HIV/STI burden and care coverage among men and transgender persons who have sex with men in Nairobi, Kenya: a crosssectional study. BMJ Open 2021;11:e055783. doi:10.1136/ bmjopen-2021-055783

- Prepublication history and additional supplemental material for this paper are available online. To view these files, please visit the journal online (http://dx.doi.org/10.1136/ bmjopen-2021-055783).

Received 02 August 2021 Accepted 03 December 2021

Check for updates

(c) Author(s) (or their employer(s)) 2021. Re-use permitted under CC BY-NC. No commercial re-use. See rights and permissions. Published by BMJ.

For numbered affiliations see end of article.

Correspondence to

Dr Adrian D Smith;

adrian.smith@dph.ox.ac.uk

\section{ABSTRACT}

Objectives The study aimed to estimate the prevalence of, and associations, with HIV and metrics of HIV care engagement in a representative population of gay, bisexual and other men who have sex with men (GBMSM) and transgender persons (TP) who have sex with men (GBMSM/TP)

Setting Urban districts of Nairobi, Kenya.

Design Cross-sectional.

Participants 608 eligible participants were identified through respondent-driven sampling over 19 waves of recruitment arising from ten seeds between May and December 2017. Inclusion criteria were: age >18 years; Nairobi residence; male sex assignment at birth or current identification as male, and recent consensual sex with male partners. Exclusion criteria were: missing or invalid recruitment coupon; repeat registration; intoxication at study visit.

Primary and secondary outcome measures HIV status measured using Determine Alere HIV 1/2 and First Response HIV 1-2.0 and GeneXpert HIV-1 Qual. Selfreported metrics of HIV status awareness, antiretroviral use and objective quantification of viral suppression using GeneXpert HIV-1 VL.

Results $26.4 \%$ (286/618) were HIV positive of whom $76.6 \%$ were status aware, $65.3 \%$ were on antiretroviral therapy (ART), and $47.4 \%$ were virally suppressed $(<50$ copies/mL). Participants 18-22 years were less likely to be status aware, be receiving ART or to have achieved viral suppression. Mean log viral load was $3.14 \log$ higher in 18-22 years compared with older participants. Bacterial sexually transmitted infections were common at both urethral and rectal sites and most infections were asymptomatic by self-report (rectal $82.2 \%$, urethral 82.3\%).

Conclusions Engagement in the HIV diagnosis and care cascade among GBMSM/TP in Nairobi is markedly better than in most sub-Saharan African countries, yet falls short of achievements for the general population in Kenya and for GBMSM in high income settings. Young GBMSM/TP are least well served by the current configuration of adult key population services, and programmes should identify and address the sexual, social and developmental needs of adolescent and young key populations.
Strengths and limitations of this study

- Population representative estimates of HIV prevalence and HIV care cascade for this key population in Nairobi, employing methods to avoid sampling biases common for marginalised group research.

- Comprehensive array of HIV and sexually transmitted infection diagnostics able to highlight the prevalence of both infections undetectable by standard Kenyan national guidelines.

- Inclusion criteria limited to adults eighteen and over, precluding insights into HIV risk and care engagement in younger adolescents.

- HIV status awareness and care engagement measures may not be accurately reporting in selfcompleted surveys, despite known benefits of computer-assisted methods to reduce social disability bias.

- Cross-sectional surveys cannot infer direction of causation where this is not implicit.

\section{BACKGROUND}

Gay, bisexual and other men who have sex with men (GBMSM) and transgender persons (TP) bear disproportionate burdens of HIV risk and HIV infection around the world, ${ }^{1-3}$ including in generalised epidemic settings in sub-Saharan Africa. ${ }^{45}$ Structural and cultural obstacles, including criminalisation, institutional homophobia and societal antipathy towards these groups continue to challenge efforts to provide equitable access to effective HIV prevention and treatment, particularly in sub-Saharan Africa. ${ }^{6}$ International agencies highlight the harmful consequences of unequal access to prevention and treatment on members of these populations and to efforts to curb national HIV epidemics. ${ }^{7}$ Yet despite clear targets for increasing status awareness and antiretroviral therapy (ART) uptake among key populations, ${ }^{8}$ very few sub-Saharan African countries conduct 
surveillance to monitor the effectiveness and coverage of treatment programmes for these populations. ${ }^{9}{ }^{10}$

Kenya has a declining generalised epidemic with an adult prevalence estimated at $4.9 \%$ in 2018 , comprehensive national prevention and treatment responses including oral pre-exposure prophylaxis (PrEP), postexposure prophylaxis, voluntary male circumcision, test and treat, and broad availability of viral load testing to support HIV care. ${ }^{11}$ The Kenya Population-based HIV Impact Assessment study demonstrated the progress toward achievement of UNAIDS 90-90-90 targets in a national survey of the general population ${ }^{12}$ : in 2018, $79.5 \%$ of adult persons living with HIV/AIDS (PLWH) (15-49years) were aware of their HIV status, of whom $90.6 \%$ were receiving ART, of whom $90.9 \%$ (or $72 \%$ of all PLWH) were virally suppressed. ${ }^{12}$ HIV surveillance is less comprehensive for GBMSM and TP in Kenya, despite a decade of research indicating high levels of need and poor service access. HIV prevalence was $18 \%$ among GBMSM/TP in Nairobi in 2010-more than three times that among the general population-and only $34 \%$ of those living with HIV were aware of their status. ${ }^{13}$ In Eastern Kenya, outcomes of HIV care for GBMSM after treatment initiation, as assessed by virological suppression at 12 months, was just $63 \%$, positively influenced by high coping self-efficacy and negatively influenced by intercourse practices thought to attract stigma. ${ }^{14}$

Kenya's HIV response is inclusive of key populations, including GBMSM and TP and national AIDS control policies include aims to enhance HIV prevention and treatment service for these populations in line with the WHO recommended package of key population interventions. ${ }^{1516}$ This has enabled a mixed model of prevention and care delivery through non-governmental organisations, private providers and state clinics largely concentrated in major cities. While diversification of sexual health provision may well have improved cultural competence and accessibility of services for these populations, there are no population representative estimates of the entire HIV diagnosis and care cascade for GBMSM/TP populations to monitor the effectiveness of this service model.

We aimed to (1) update the prevalence of HIV and other sexually-transmitted infections (STIs) in a population representative sample of cisgender male and TP who have sex with men living in Nairobi, (2) describe the HIV care cascade and viral load among GBMSM and TP living with HIV and (3) assess associations with prevalence of both HIV infection and detectable viraemia in this context.

\section{METHODS}

\section{Recruitment and sampling}

Respondent-driven sampling (RDS) was used to recruit 618 participants between May and December 2017 following established methods. ${ }^{17}$ Seed participants were identified to the study by three community organisations who provide services to GBMSM communities in Nairobi (Gay and Lesbian Coalition of Kenya (GALCK), Ishtar MSM and Health Options for Young Men on STI/ HIV/AIDS (HOYMAS). Following formative qualitative research, ten seeds were chosen to optimise diversity in age, marital status, gender identity, socioeconomic status and district of residence within Nairobi County.

Each participant was issued two recruitment coupons and instructions on how to recruit further eligible participants from their social networks. Inclusion criteria were: possession of a valid study coupon; age 18 or over; male gender assignment at birth or current identification as a man; residence within $50 \mathrm{~km}$ of Nairobi, and consensual anal or oral sexual activity with a man in the previous twelve months. Coupons detailed the location and contact details for the study site but disclosed no information about the purpose of the study. Coupons were uniquely numbered to verify recruiter-recruit links and coupon legitimacy. The opportunity for coupon duplication was reduced by use of non-standard grade watermarked paper, date stamping and limited period of validity after issue. Participants were reimbursed Ksh300 ( US\$3) for each recruit they referred to the study who subsequently participated.

\section{Study procedures}

Seeds and coupon recipients who satisfied eligibility criteria underwent informed consent procedures with study staff. Recipients were ineligible if they reported coupon receipt from a stranger, coercion to attend or previous participation in the study. Unique identity was established using a commercially available digital fingerprint scanner.

Participant characteristics and behaviour were collected via self-completed SurveyGizmo questionnaire implemented in English and Kiswahili on touch-screen tablets taking approximately $90 \mathrm{~min}$ to complete (online supplemental material). The questionnaire covered multiple domains including demographic characteristics; sexual behaviour; alcohol and other substance use; knowledge of HIV transmission risks; use of existing HIV/STI prevention methods; recent anogenital symptoms suggestive of STI; experiences of sexuality-related stigma, discrimination or violence. ${ }^{18}{ }^{19}$ Sex was defined as any occurrence of anal or vaginal intercourse in the reference period. Transactional sex was defined as sex in exchange for money, gifts or favours. Sex against the will of the participant was defined as any episode of being physically forced or coerced into sex when this was unwanted. In addition, the questionnaire included prevalidated measures of alcohol use and dependence. ${ }^{20}$ Social network size was elicited from a sequence of questions yielding the number of MSM, over the age of 18 living in Nairobi and met in person in the last 2 weeks.

Participants were offered HIV counselling and rapid testing following Kenyan HIV Testing Services (HTS) guidelines using two commercial rapid diagnostic kits (RDT: Determine Alere HIV 1/2 and First Response HIV 
1-2.0). ${ }^{21}$ Blood specimens were tested for syphilis (treponemal haemagglutination (TPHA) and rapid plasma reagin (RPR) tests), hepatitis $B$ surface antigen and hepatitis $\mathrm{C}$ antibody (Mircrowell ELISA, Bios USA) and qualitative or quantitative HIV-1 PCR conditional on rapid test results (GeneXpert HIV-1 Qual or HIV-1 VL). Urine and rectal swabs were collected and tested for Neisseria gonorrhoea (NG) and Chlamydia trachomatis (CT) using PCR (GeneXpert CTNG).

HIV care continuum measures were based on Centers for Disease Control guidelines with a viral suppression threshold of $<50$ copies $/ \mathrm{mL}^{22}$ Self-reported HIV status awareness and use of ART were collected both by computer-assisted survey and as part of HTS. Measures of linkage to care within 6 months of diagnosis and retention in care over the past 12 months were only elicited in the survey.

PLWHA not reporting receipt of care were referred to government services for initiation of ART. HIV negative participants were referred for PrEP eligibility assessment. Treatment for other STIs was provided free and according to national guidelines. Condoms and water-based lubricants were freely available in the study clinic as was information about sexual risk reduction and other GBMSM/ TP-affirming local sexual health services. Participants were compensated Ksh500 ( US\$5) for completing study procedures, as approved by the ethics review board.

\section{Patient and public involvement}

Patient and public organisations were involved in the design, management and dissemination of the project. The original research protocol was developed and adapted after consultation with a number of communitybased organisations representing key populations in Nairobi, including the GALCK, HOYMAS, Ishtar MSM and the Sex Workers Outreach Programme (SWOP). Early in study planning, we submitted draft protocol and instruments for consideration of the G10 committee, a research sub-committee of GALCK. This resulted in the ratification of study objectives from community members and multiple improvements to study instruments. The G10 commended the investigators on the extent of community consultation conducted in preparation for the study, including our evidence of Good Participatory Practice. The G10 acted as the community advisory board for the duration of the study, offering prompt feedback on the experience of participants and wider perceived threats to study procedures or participants, such as election disruptions. Staff from HOYMAS, Ishtar MSM and SWOP were employed in study roles on reception and on social media as service navigators for participants seeking services or support outside the research. At study closure, we presented research findings directly to participants at a public meeting, in person and in writing to the boards of all key population serving organisations in Nairobi, as well as to formal policy-making agencies.

\section{Statistical methods}

RDS diagnostics including visualisation of recruitment chains, convergence and seed dependence, and statistical assessment of recruitment homophily were analysed using the $r d s$ library for R V.3.4.0. ${ }^{2324}$ Crude and sample weighted estimates (RDS-II method and excluding seeds) ${ }^{23}$ of the prevalence of sociodemographic and behavioural factors, lab-confirmed and self-reported STIs and HIV cascade measures (for PLWHA only) are presented in accordance with good practice. ${ }^{25}$ Given evidence of under-reporting of status awareness and ART use in HTS and surveys alone (see online supplemental material), a composite cascade was derived combining both sources and treating any report of HIV awareness or treatment receipt as a positive response. Age and partner count quintiles among PLWHA were coded and used throughout for consistency Analysis stratified by gender identity has been published previously. $^{26}$

Associations with HIV prevalence in the entire sample, and prevalence of detectable HIV viraemia among PLWHA only, were assessed using robust Poisson regression with a non-clustered sandwich estimator ${ }^{27}$ for an unbiased estimate of the prevalence ratio. ${ }^{28}$ Multivariable models were specified including sociodemographic (model 1) or full (model 2) covariates associated with outcome at $\mathrm{p}<0.100$. STIs other than HIV were not included as independent covariates in adjusted models given the strong likelihood of dependence on behavioural determinants of HIV risk. Given the bimodal distribution of viral load among PLWHA, comparisons between quantitative VL measures were limited to non-parametric significance testing (Kruskall-Wallis test) and distribution visualisation (Epanechnikov kernels). All analyses of association excluded purposively sampled seeds and were not sample weighted (given both the known risk of bias in applying network weights to multivariate analyses ${ }^{29}$ and the correlation of pertinent behavioural measures with social network degree). Less than $5 \%$ of covariate measures were missing and were included in models as dummy variables. Analyses were performed in Stata V.16.

All participants provided separate written informed consent to the questionnaire, sample collection and sample storage, and were able to withdraw from any portion of the study.

\section{RESULTS}

A total of 761 individuals presented to the study site with the intention of participation. A total of 124 were ineligible due to fake or missing coupons, repeat attendance, intoxication or failure to meet inclusion criteria. Of the 637 individuals with confirmed eligibility, 29 declined participation during consent procedures. Of 608 recruits and 10 seeds completing informed consent, one participant declined blood testing and six declined rectal swabs. Four seeds accounted for $516(84.9 \%)$ recruits. Depth of recruitment ranged from 1 to 19 waves per seed (median 7) (online supplemental material). 


\begin{tabular}{|c|c|c|c|}
\hline & $\mathbf{N}$ & $\begin{array}{l}\text { Crude } \\
\%\end{array}$ & $\begin{array}{l}\text { RDS \% } \\
\text { N=608 }(95 \% \text { Cl)* }\end{array}$ \\
\hline \multicolumn{4}{|l|}{ Age in years } \\
\hline $18-22$ & $225 / 618$ & 36.4 & 38.2 (33.8 to 42.8$)$ \\
\hline $23-26$ & $169 / 618$ & 27.4 & $27.2(23.4$ to 31.5$)$ \\
\hline $27-32$ & $136 / 618$ & 22.0 & 20.6 (17.2 to 24.5$)$ \\
\hline $33+$ & $88 / 618$ & 14.2 & $14.0(11.1$ to 17.5$)$ \\
\hline \multicolumn{4}{|l|}{ Employment } \\
\hline $\begin{array}{l}\text { Salaried (full or } \\
\text { part time) }\end{array}$ & $179 / 608$ & 29.4 & 28.1 (24.1 to 32.4$)$ \\
\hline Self employed & $159 / 608$ & 26.2 & 27.4 (23.5 to 31.8$)$ \\
\hline Unemployed & $247 / 608$ & 40.6 & 41.7 (37.2 to 46.3$)$ \\
\hline Other & $23 / 608$ & 3.8 & 2.9 (1.7 to 4.7$)$ \\
\hline \multicolumn{4}{|l|}{ Education } \\
\hline Primary & $111 / 611$ & 18.2 & $18.1(14.8$ to 21.9$)$ \\
\hline Secondary & $329 / 611$ & 53.9 & $55.0(50.4$ to 59.6$)$ \\
\hline Higher & $171 / 611$ & 28.0 & 26.9 (23.0 to 31.1$)$ \\
\hline \multicolumn{4}{|c|}{ Income (Kenya Shillings per month) } \\
\hline$<\mathrm{Ksh} 5 \mathrm{~K}$ & $224 / 574$ & 39.0 & 40.9 (36.2 to 45.7$)$ \\
\hline $\begin{array}{l}\text { Ksh5K to } \\
<\text { Ksh10K }\end{array}$ & $166 / 574$ & 28.9 & 27.7 (23.6 to 32.1$)$ \\
\hline Ksh10K+ & $184 / 574$ & 32.1 & 31.5 (27.2 to 36.1$)$ \\
\hline \multicolumn{4}{|l|}{ Country of birth } \\
\hline Kenya & $484 / 607$ & 79.7 & 78.8 (74.6 to 82.4$)$ \\
\hline $\begin{array}{l}\text { Other African } \\
\text { country }\end{array}$ & $112 / 607$ & 18.5 & 19.8 (16.3 to 23.9$)$ \\
\hline $\begin{array}{l}\text { Non-African } \\
\text { country }\end{array}$ & $11 / 607$ & 1.8 & 1.4 (0.7 to 2.9$)$ \\
\hline \multicolumn{4}{|l|}{ Sexual identity } \\
\hline Gay/homosexual & $448 / 609$ & 73.6 & 73.2 (69.0 to 77.2$)$ \\
\hline Bisexual & $143 / 609$ & 23.5 & 23.4 (19.7 to 27.6$)$ \\
\hline Other & $18 / 609$ & 3.0 & 3.3 (2.0 to 5.6$)$ \\
\hline \multicolumn{4}{|l|}{ Gender identity } \\
\hline Cisgender male & $522 / 618$ & 84.5 & 85.0 (81.5 to 88.0$)$ \\
\hline Transfeminine & $70 / 618$ & 11.3 & 11.3 (8.7 to 14.5$)$ \\
\hline Othert & $26 / 618$ & 4.2 & 3.7 (2.6 to 5.7 ) \\
\hline
\end{tabular}

Sexual behaviour-male partners

Male sexual partners (last 3 months)

\begin{tabular}{|lrrl}
\hline None & $74 / 618$ & 12.0 & $12.5(9.7$ to 15.9$)$ \\
\hline $1-3$ & $405 / 618$ & 65.5 & $72.7(68.5$ to 76.5$)$ \\
\hline $\begin{array}{l}\text { 4 or more } \\
\text { Sold sex (last }\end{array}$ & $139 / 618$ & 22.5 & $14.8(12.1$ to 18.0$)$ \\
$\begin{array}{l}\text { 12 months) } \\
\text { Paid for sex (last }\end{array}$ & $177 / 614$ & 28.8 & 28.2 (24.2 to 32.6$)$ \\
\hline
\end{tabular}

Anal intercourse with male partner (last 3 months)

\begin{tabular}{|c|c|c|c|}
\hline None & $77 / 618$ & 12.5 & $13.1(10.2$ to 16.5$)$ \\
\hline Receptive only & $158 / 618$ & 25.6 & 24.8 (21.1 to 29.0$)$ \\
\hline Insertive only & $220 / 618$ & 35.6 & 37.9 (33.5 to 42.5$)$ \\
\hline $\begin{array}{l}\text { Receptive and } \\
\text { insertive }\end{array}$ & $163 / 618$ & 26.4 & 24.2 (20.6 to 28.3 ) \\
\hline
\end{tabular}

Continued
Table 1 shows the characteristics of enrolled participants. Median age was 24 years (IQR 21-29) with $38.2 \%$ between the ages of $18-22$ years. Most participants reported having attended postprimary education, however, a high proportion of participants reported being unemployed. A minority of participants reported a birthplace outside of Kenya, predominantly in neighbouring East African countries, in particular Uganda $(n=90)$. Three-quarters of participants self-identified as gay or homosexual, and $15.0 \%$ self-identified as noncisgender (predominantly transfeminine or female). Only $35.3 \%$ (30.9\%-39.9\%, 229/580) reported having been in contact with community-based organisations targeting GBMSM/TP during the previous year.

Participants reported a median of two male sexual partners in the past 3 months (IQR 1-3). Male partner counts were higher among the $44 \%$ of participants who reported selling sex to men in the past year (median 3 vs 2 different partners in the last 3 months, KruskallWallis $\mathrm{p}<0.001)$. Forty-nine per cent $(44.5-53.6)$ reported receptive anal intercourse in the past 3 months, of whom $54.2 \%(175 / 32147.8-60.5)$ reported at least one episode that was condomless. $62.1 \%(57.6-66.5)$ reported insertive anal sex with male partners over the same period, of whom $44.2 \%(175 / 383$ 38.5-50.0) at least one condomless episode. Over a quarter of participants reported female sexual partners over that period and participants were similarly likely to have sold sex to, or purchased sex from, females. A significant proportion of participants reported experiencing sex against their will in the last 12 months. Among HIV negative participants, 59.2\% (237/396 53.4\%-64.6\%) reported HIV testing within the last 6 months and $4.4 \%(25 / 4302.7 \%-7.0 \%)$ reported current oral PrEP use.

A total of 186 participants tested HIV positive (crude $30.1 \%$, RDS-II $26.4 \%$ ). Two individuals were positive only on PCR testing, representing $2.1 \%(2 / 186,0.5-8.2 \%)$ of PLWHA or $0.76 \%(2 / 426,0.18-0.30 \%)$ of participants testing negative by the national RDT algorithm. Five participants had evidence of active syphilis infection, and hepatitis B and C prevalence was low. Laboratoryconfirmed rectal STIs were more prevalent than urethral STIs, and rectal NG was the most common site-specific STI. $82.2 \%$ confirmed rectal infections $(90 / 106,72.0$ $89.3 \%)$ and $82.3 \%$ confirmed urethral infections $(49 / 60$, $68.8-90.8)$ were asymptomatic on self-report. HIV prevalence was crudely associated with prevalent laboratoryconfirmed rectal NG (PR 2.19 (1.72-2.78), $\mathrm{p}<0.001)$, rectal CT (PR 1.49 (1.06-2.08), $\mathrm{p}=0.020)$ and urethral NG (PR $1.92(1.34-2.75), \mathrm{p}<0.001)$ and with self-reported symptoms at rectal (PR $2.37(1.85-3.05), \mathrm{p}<0.001)$ and urethral sites (PR 2.00 (1.49-2.69), p<0.001)

Table 2 shows crude and adjusted variable associations with HIV status. Across models, increasing age was strongly associated with increasing HIV prevalence. In fully adjusted models HIV prevalence rose on average $6.4 \%$ per year of age $(5.0 \%-7.9 \%), \mathrm{p}<0.001)$, from $13 \%$ among $18-22$ years to $48.9 \%$ among those over 32 years 


\begin{tabular}{|c|c|c|c|}
\hline & $\mathbf{N}$ & $\begin{array}{l}\text { Crude } \\
\%\end{array}$ & $\begin{array}{l}\text { RDS \% } \\
\mathrm{N}=608(95 \% \mathrm{Cl})^{*}\end{array}$ \\
\hline \multicolumn{4}{|c|}{$\begin{array}{l}\text { Condomless anal intercourse (last } 3 \\
\text { months) }\end{array}$} \\
\hline None & $353 / 618$ & 57.1 & $58.2(53.6$ to 62.6$)$ \\
\hline Receptive only & $90 / 618$ & 14.6 & $14.4(11.5$ to 18.0$)$ \\
\hline Insertive only & $90 / 618$ & 14.6 & $14.9(11.9$ to 18.5$)$ \\
\hline Both & $85 / 618$ & 13.8 & 12.5 (9.8 to 15.8$)$ \\
\hline $\begin{array}{l}\text { Condomless anal } \\
\text { intercourse with } \\
\text { male partners } \\
\text { (last } 3 \text { months) }\end{array}$ & $265 / 618$ & 42.9 & 41.8 (37.4 to 46.4$)$ \\
\hline \multicolumn{4}{|c|}{ Sexual behaviour-female partners } \\
\hline $\begin{array}{l}\text { Female sexual } \\
\text { partner (last } 3 \\
\text { months) }\end{array}$ & $174 / 618$ & 28.2 & 28.3 (24.4 to 32.7$)$ \\
\hline $\begin{array}{l}\text { Sold sex to } \\
\text { female partner } \\
\text { (last } 12 \text { months) }\end{array}$ & $58 / 615$ & 9.4 & 9.0 (6.7 to 12.1$)$ \\
\hline $\begin{array}{l}\text { Paid for sex with } \\
\text { female partner } \\
\text { (last } 12 \text { months) }\end{array}$ & $67 / 614$ & 10.9 & 11.2 (8.6 to 14.6$)$ \\
\hline $\begin{array}{l}\text { Condomless } \\
\text { intercourse with } \\
\text { female partners } \\
\text { (last } 3 \text { months) }\end{array}$ & $94 / 618$ & 15.2 & 15.9 (12.8 to 19.6$)$ \\
\hline \multicolumn{4}{|l|}{ Sexual violence } \\
\hline $\begin{array}{l}\text { Forced to have } \\
\text { sex against will } \\
\text { (last } 12 \text { months) }\end{array}$ & $87 / 615$ & 14.1 & $13.1(10.3$ to 16.5$)$ \\
\hline \multicolumn{4}{|l|}{$\begin{array}{l}\text { Substance use } \\
\text { behaviour }\end{array}$} \\
\hline \multicolumn{4}{|l|}{$\begin{array}{l}\text { Alcohol use (last } \\
2 \text { weeks) }\end{array}$} \\
\hline Never & $261 / 618$ & 42.2 & 45.1 (40.6 to 49.7$)$ \\
\hline Monthly & $269 / 618$ & 43.5 & 42.5 (38.0 to 47.1$)$ \\
\hline Weekly & $88 / 618$ & 14.2 & 12.4 (9.8 to 15.7$)$ \\
\hline $\begin{array}{l}\text { Other substance } \\
\text { use }(3 \mathrm{~m}) \ddagger\end{array}$ & $51 / 618$ & 8.3 & 8.0 (5.8 to 10.8$)$ \\
\hline \multicolumn{4}{|l|}{ HIV } \\
\hline $\begin{array}{l}\text { HIV-RNA } \\
\text { (GeneXpert HIV- } \\
1 \text { Qual) only }\end{array}$ & $2 / 617$ & 0.3 & 0.6 (0.1 to 2.2 ) \\
\hline $\begin{array}{l}\text { Rapid test } \\
\text { (determine/first } \\
\text { response) }\end{array}$ & $184 / 617$ & 29.8 & 25.8 (22.1 to 30.0$)$ \\
\hline Total & $186 / 618$ & 30.1 & 26.4 (22.6 to 30.6$)$ \\
\hline \multicolumn{4}{|l|}{ Syphilis } \\
\hline $\begin{array}{l}\text { Positive (TPHA+ } \\
\text { / RPR >3) }\end{array}$ & $5 / 614$ & 0.8 & 1.1 (0.4 to 2.8$)$ \\
\hline \multicolumn{4}{|l|}{ Hepatitis B } \\
\hline $\begin{array}{l}\text { Positive hepatitis } \\
\text { B surface } \\
\text { antigen (HBsAg) }\end{array}$ & $30 / 614$ & 4.9 & 4.4 (2.8 to 6.7 ) \\
\hline Hepatitis C & & & \\
\hline
\end{tabular}

Continued

\begin{tabular}{|c|c|c|c|}
\hline & $\mathbf{N}$ & $\begin{array}{l}\text { Crude } \\
\%\end{array}$ & $\begin{array}{l}\text { RDS \% } \\
\mathrm{N}=608(95 \% \mathrm{Cl})^{*}\end{array}$ \\
\hline $\begin{array}{l}\text { Positive anti- } \\
\text { hepatitis C virus } \\
\text { antibody (anti- } \\
\text { HCV Ab) }\end{array}$ & $3 / 614$ & 0.5 & 0.4 (0.1 to 1.7$)$ \\
\hline \multicolumn{4}{|l|}{ Rectal STIs } \\
\hline $\begin{array}{l}\text { Lab-confirmed } \\
\text { rectal } N \text {. } \\
\text { gonorrhoeae }\end{array}$ & $76 / 611$ & 12.4 & $13.2(10.4$ to 16.8$)$ \\
\hline $\begin{array}{l}\text { Lab-confirmed } \\
\text { rectal } C \text {. } \\
\text { trachomatis }\end{array}$ & $53 / 611$ & 8.7 & 8.1 (5.9 to 10.9 ) \\
\hline $\begin{array}{l}\text { Self-reported } \\
\text { rectal STI } \\
\text { symptoms }\end{array}$ & $51 / 609$ & 8.4 & 8.6 (6.3 to 11.6$)$ \\
\hline \multicolumn{4}{|l|}{ Urethral STIs } \\
\hline $\begin{array}{l}\text { Lab-confirmed } \\
\text { urethral } N \text {. } \\
\text { gonnorhoeae }\end{array}$ & $27 / 614$ & 4.4 & 4.4 (2.9 to 6.7$)$ \\
\hline $\begin{array}{l}\text { Lab-confirmed } \\
\text { urethral } C \text {. } \\
\text { trachomatis }\end{array}$ & $39 / 614$ & 6.4 & 7.3 (5.2 to 10.3 ) \\
\hline $\begin{array}{l}\text { Self-reported } \\
\text { urethral STI } \\
\text { symptoms }\end{array}$ & $43 / 601$ & 7.2 & 6.4 (4.5 to 9.0$)$ \\
\hline
\end{tabular}

*Seeds dropped and RDS-II weighting.

†'Other' includes transmasculine participants and participants not currently identifying with the terms male, female or transgender. łEcstacy, amphetimines, mephamphetamine, mephedrone, heroin, gamma-hydroxybutyric acid (GHB), rohypnol, cocacine, crack cocaine, benzene, amyl nitrite.

RDS, respondent-driven sampling; STIs, sexually transmitted infections.

of age. Participants reporting a birthplace outside Kenya but within Africa had less than half the HIV prevalence of Kenyan-born participants in all models. Transfeminine participants had a 50\% higher prevalence than cisgender GBMSM after adjustment for sociodemographic factors, yet not after adjustment for behavioural factors. In crude analyses, HIV infection was associated with higher male partner counts, selling sex to men and receptive anal intercourse. In adjusted models, recent receptive anal intercourse was also independently associated with HIV, while recent condomless sex with a female partner was inversely associated with HIV prevalence.

Figure 1A shows the composite, RDS-II-adjusted care cascade among participants with HIV infection (see online supplemental material for cascades based on survey and HTS measures only). 97.9\% (91.8\%-99.5\%, RDS-II, $\mathrm{n}=184$ ) were detected by the HTS regimen, $76.6 \%$ (68.2\%-83.3\%, RDS-II, $\mathrm{n}=137)$ reported status awareness and $65.3 \%(56.6 \%-73.2 \%$, RDS-II, $\mathrm{n}=129)$ reported currently receiving ART. $47.4 \%$ (38.9\%-56.0\%), RDS-II, $\mathrm{n}=92)$ of PLWHA were virally supressed $(<50$ copies/ $\mathrm{mL}$ ). Median viral load was highest among two PCR positive participants with negative rapid tests $\left(6.46 \log _{10}\right.$ 


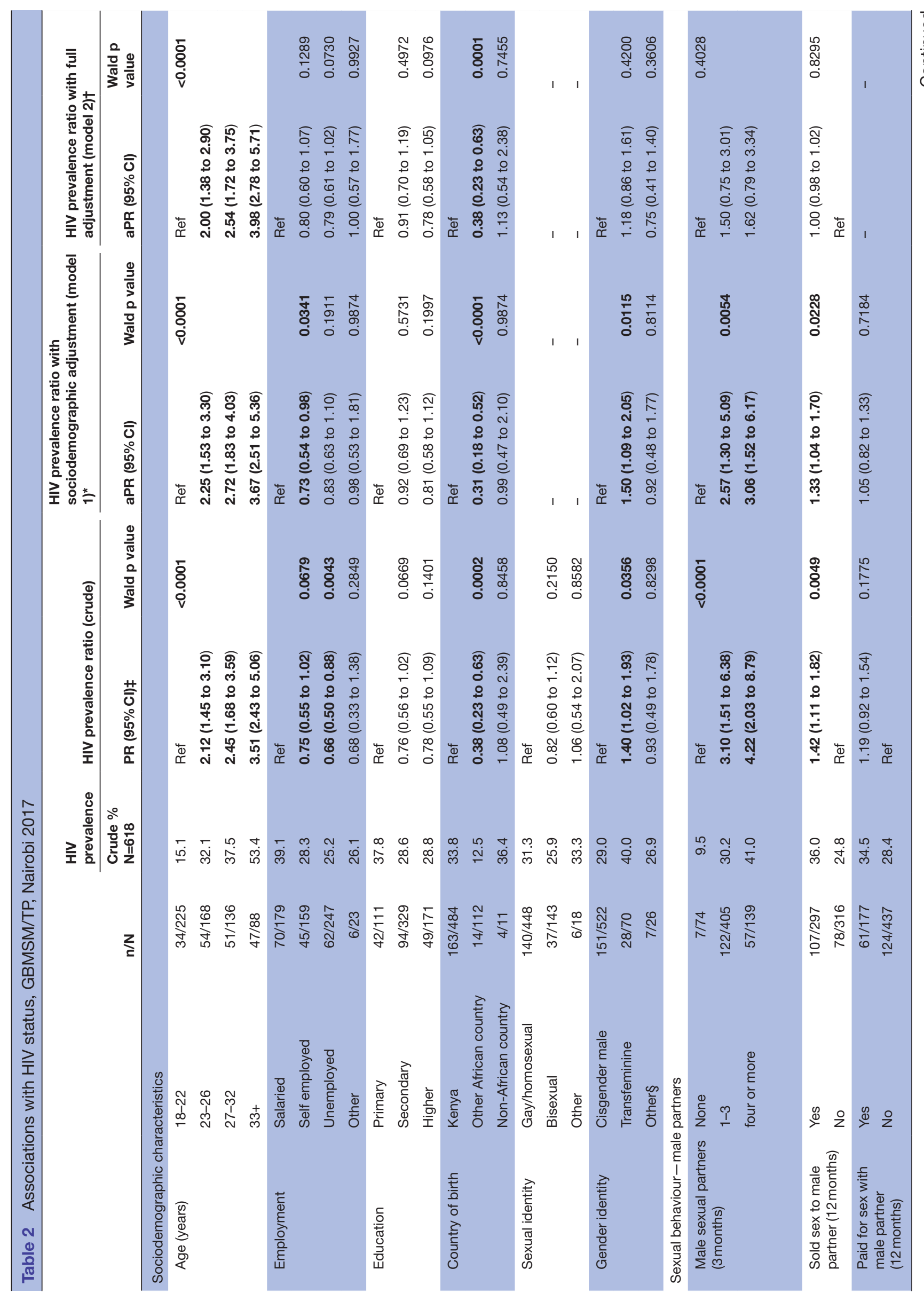




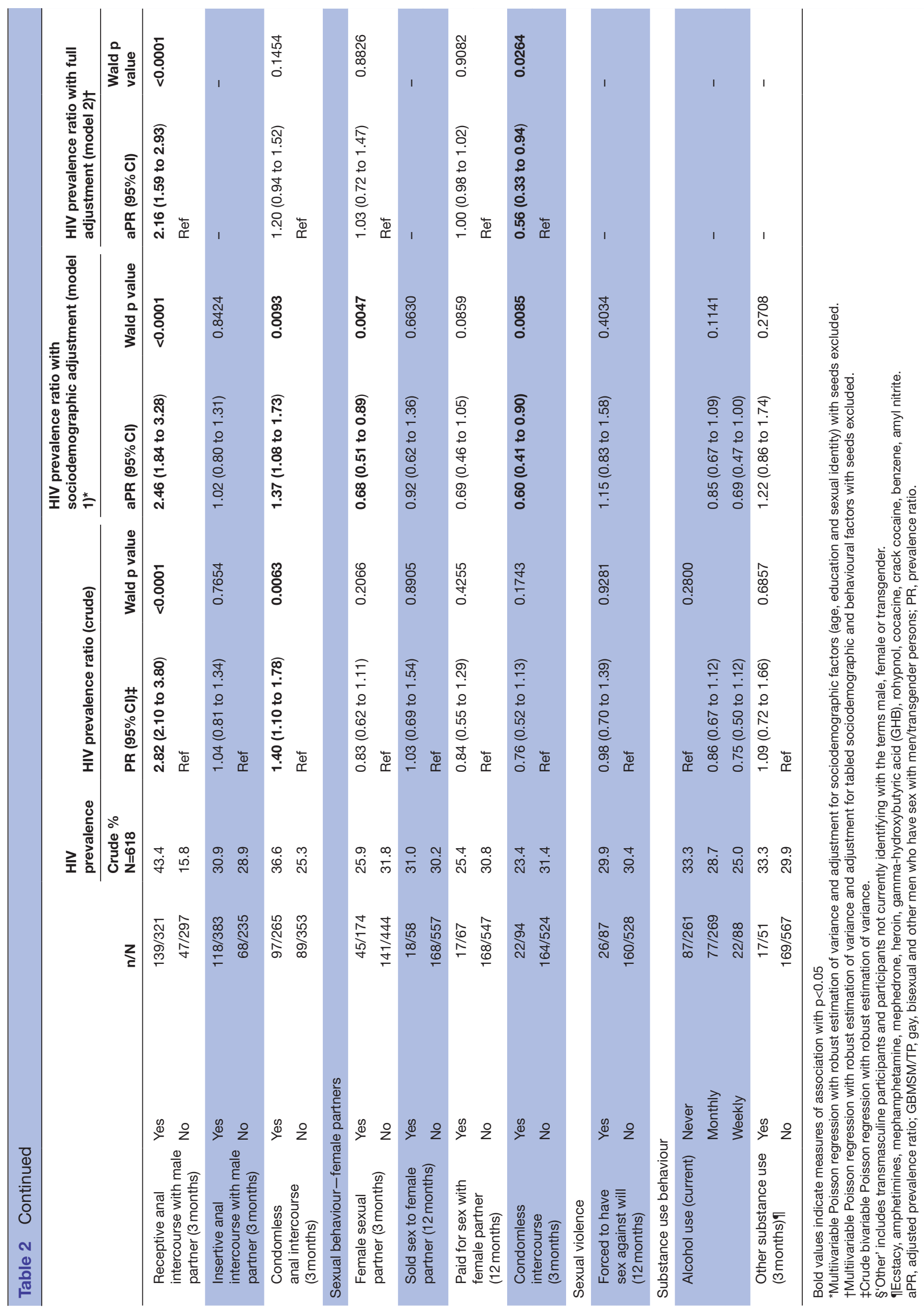



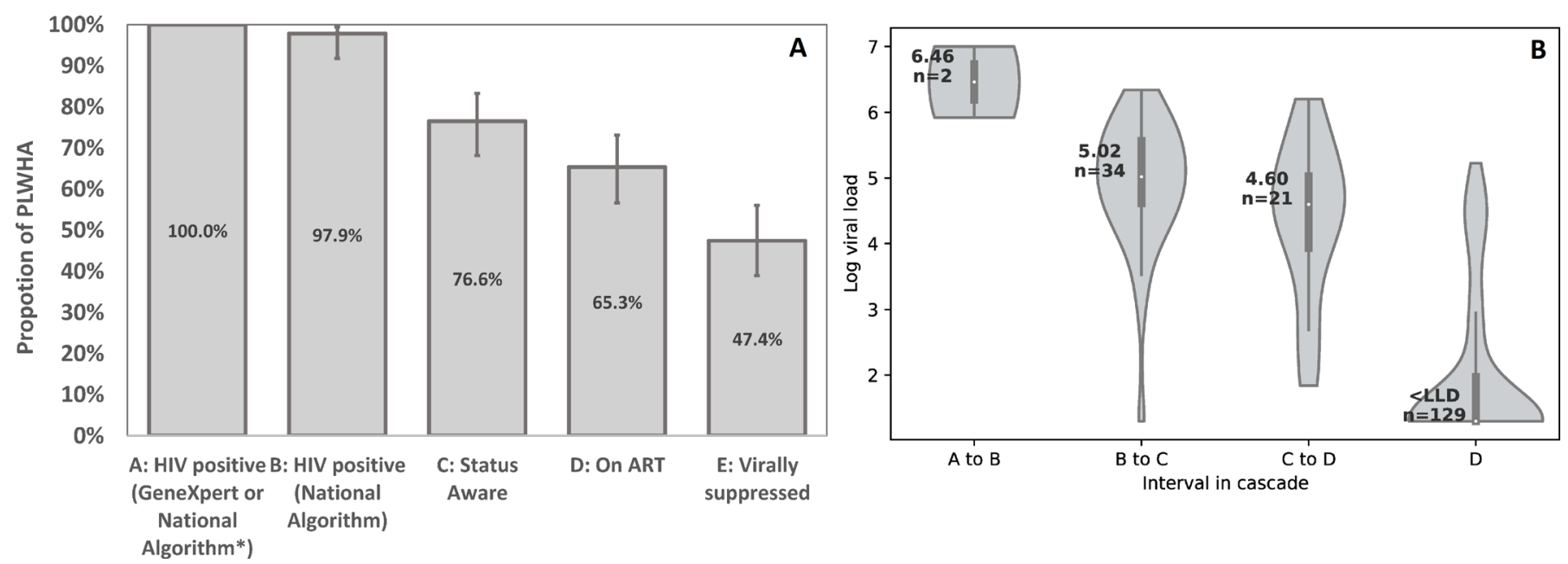

Figure 1 (A) Diagnosis and care cascade among GBMSM/TP living with HIV. *Kenyan National HIV testing algorithm: Serial Determine Alere and First Response Rapid Diagnostic Tests. Point estimates are RDS adjusted and exclude seeds. Error bars represent $95 \%$ Cls. (B) Log viral load median and distribution by level of diagnosis and care cascade engagement. Intervals: (A, B) HIV positive only on GeneXpert; $(B, C)$ HIV positive on RDT but participant not status aware; (C, D) - Participant reports status awareness but reports no current use of ART; (D) Participants reports current use of ART. Vertical bars represent IQR, white dots represent median log viral load. Median and category sample size stated in label. $<$ LLD: $\left(40 \mathrm{copies} / \mathrm{mm}^{3}\right)$. $\mathrm{P}$ values from Kruskall-Wallis equality of populations rank test. ART, antiretroviral therapy; GBMSM/TP, gay, bisexual and other men who have sex with men/transgender persons; LLD, lower limit of detection; PLWHA, persons living with HIV/AIDS; RDS, respondentdriven sampling.

copies $/ \mathrm{mL}$ ), and declined significantly by each progressive step across the care continuum (figure 1B). Among 131 participants declaring receipt of HIV care, 61 (41.7 (31.9-52.2\%) last received care in a community organisation, $44(36.9 \%(27.4 \%-47.6 \%)$ in a public hospital, and $26(21.5 \%(14.1 \%-31.3 \%)$ from a private provider.

Factors associated with detectable viraemia among PLHWA are shown in table 3. A strong and significant inverse trend was apparent between increasing age and prevalence of detectable viraemia in both crude and adjusted models. On average, the prevalence of detectable HIV viraemia decreased by $4.2 \%$ per year of age $(1.8 \%-6.6 \%$, test for linear trend, $\mathrm{p}=0.0001)$. These trends were apparent across all metrics of the HIV care cascade (figure 2A). Median log viral load among participants aged 18-22 was significantly higher than older age groups (4.44 vs $1.30 \log _{10}$ copies/mL, Kruskall-Wallis $p=0.0012$, figure $2 B$ ), and both participants with acute HIV infections were within this youngest age-group. Increasing levels of education attendance were also associated with a declining level of viral detection among PLWHA, however, this trend was not statistically significant. Behavioural correlates of prevalent HIV viraemia in the demographically adjusted model (model 1 ) were payment for sex in the last 3 months (with either male or female partners) and recent condomless anal intercourse with female partners, while there was an inverse association with recently selling sex to male partners.

\section{DISCUSSION}

Over a quarter of GBMSM and TP in Nairobi now live with HIV infection. Our HIV prevalence estimate is higher than previous RDS estimates from the same city in $2010\left(18.2 \%^{13}\right)$ as well as convenience samples elsewhere in Kenya $\left(19.8 \%\right.$ Malindi $2010^{30} ; 16.6 \%$ Kisumu 2015). ${ }^{31}$ Extrapolation of the observed proportion with evidence of acute/early HIV infection not detectable by fourth generation testing (assuming a conservative estimate of 14-day window period between GeneXpert and RDT detection) suggests an annual HIV incident risk of $15 \%(4 \%-58 \%)$. Persistently high HIV/STI risk is consistent with high reported levels of known behavioural and biological acquisition risks that have not improved over time $^{13}$ : over $40 \%$ of GBMSM/TP report recent condomless anal intercourse and transactional partnerships, and a high proportion have concurrent, often asymptomatic, STIs. The frequent reports of sex with female partners, including transactional sex, among GBMSM is consistent with previous research in Kenya, as is the lower observed HIV risk among bisexually active as opposed to exclusive GBMSM likely due to differences in role behaviour and network prevalence. ${ }^{32}$ Antiretroviral prevention uptake remains poor for these populations and while the national PrEP programme was in the process of deployment during this study, subsequent evaluation since confirms inadequate uptake and persistence among GBMSM/TP. ${ }^{33}$

However, this study does highlight significant progress in reaching key populations with HIV testing and care. We estimate that three-quarters of GBMSM/TP living with HIV in Nairobi are aware of their status and nearly half have been supported to achieve viral suppression, analogous to 77-85-73 against UNAIDS targets. This cascade compares favourably to collated GMSM/TP cascade data from elsewhere in sub-Saharan Africa (18-53-76) ${ }^{9}$ 


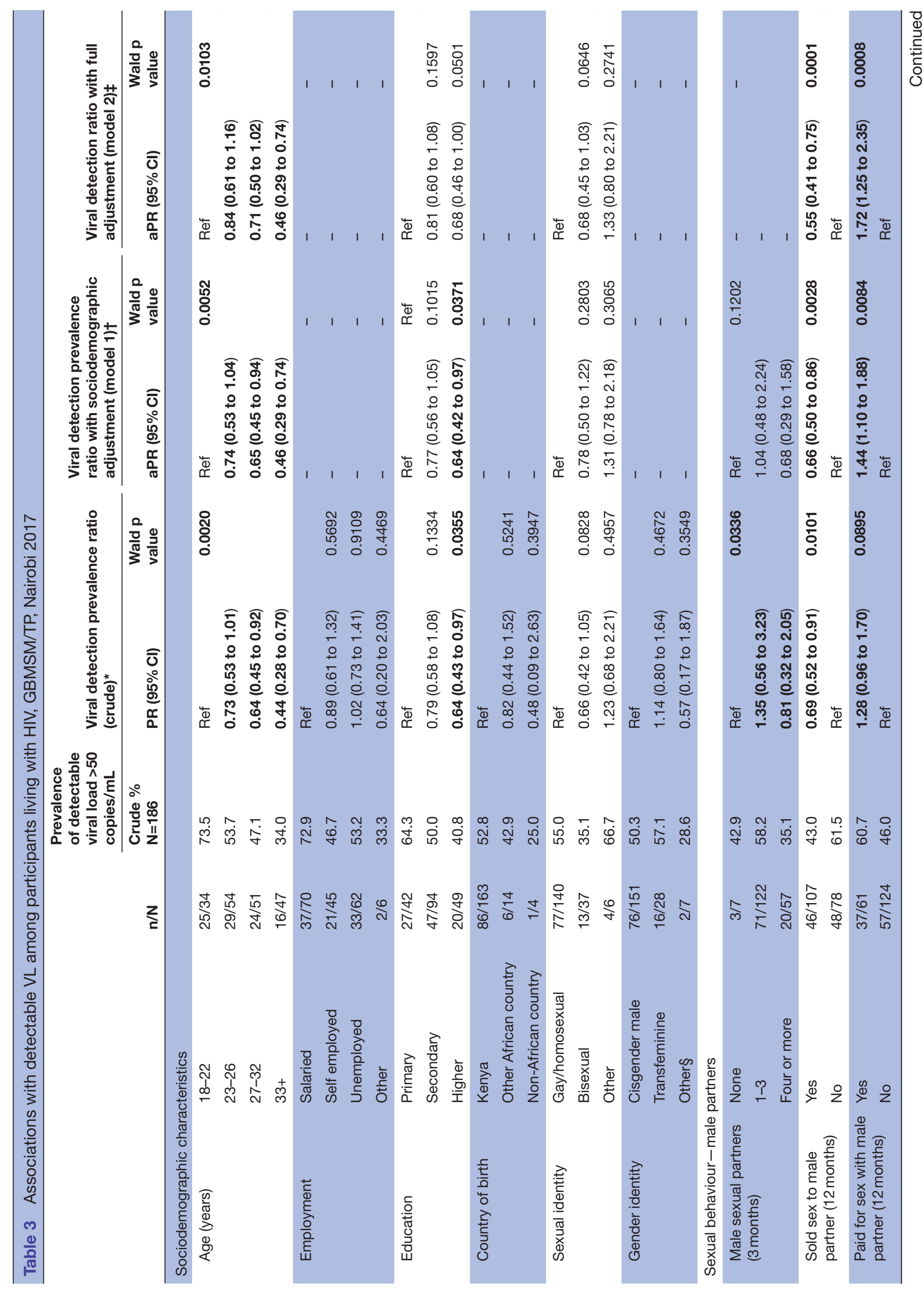




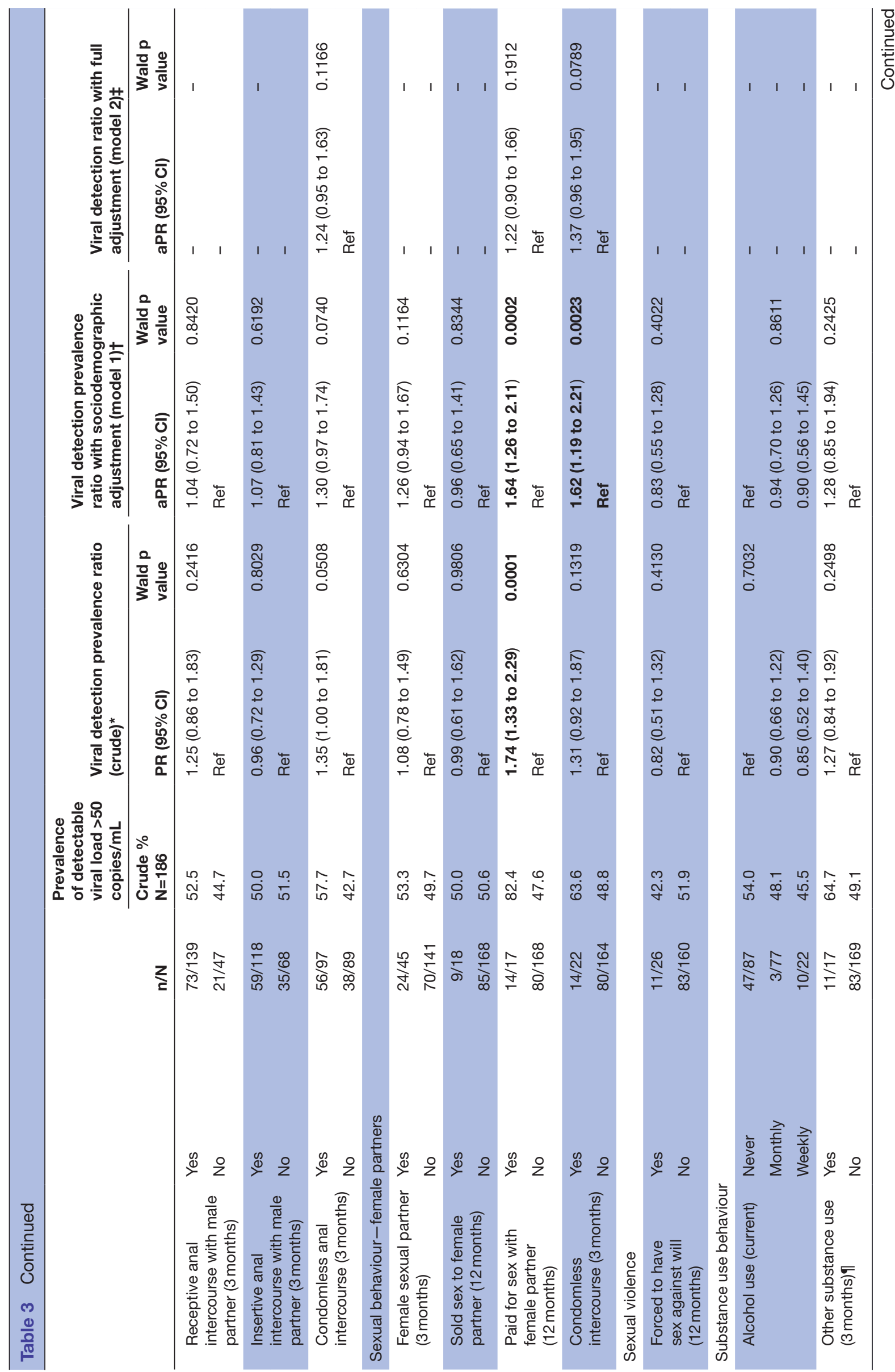




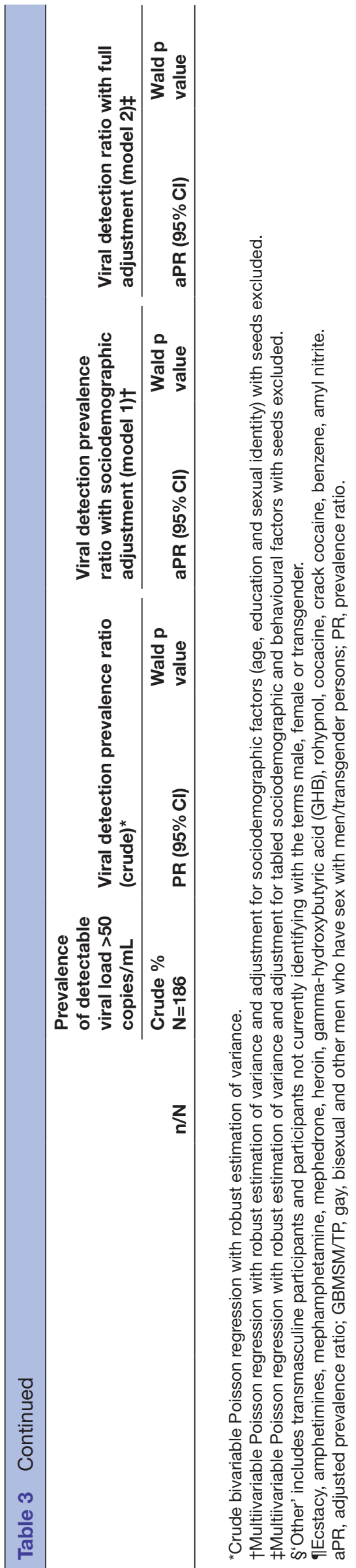

as well as to that reported in global self-reported surveys (NA-82-58). ${ }^{34}$ This is by no means a small achievement of HIV programming within a societal context of homophobic discrimination and criminalisation of same sex behaviour ${ }^{6}$ and represents marked improvements in access to HIV care that will directly translate into better health outcomes for GBMSM and TP living with HIV. However, cascades fall behind those for PLWH in the Kenyan general population (80-96-91 in 2017) ${ }^{12}$ and for GBMSM and transgender in high-income settings. ${ }^{35}$

There is increasing evidence demonstrating the effectiveness of mHealth ${ }^{36} 37$ and other social media interventions ${ }^{38}$ on testing uptake and linkage to HIV services for GBMSM, while effects on retention and care outcomes are as yet inconclusive. Internet based interventions may be highly suited to the context of this study since internet services and social media are widely accessible and utilised among these populations. ${ }^{39}$ However, any such intervention requires cautious adaptation and testing given associated risks arising from disclosure these services that has also been reported in this context. LINKAGES recommend peer navigation strategies as an element of core HIV-related interventions for key populations, ${ }^{40}$ yet such strategies remain underused in Kenyan key population programmes despite local evidence of the effectiveness of this approach on care outcomes. ${ }^{41}$ Most of the community-based organisations serving GBMSM/TP in Nairobi already use various models of peer outreach for client engagement, and the addition of quality assured peer navigation could be both complementary and impactful.

Inequalities in coverage of HIV diagnosis and care for persons living with HIV were principally driven by age. We observed strong positive associations between increasing age and virological suppression, as well as other metrics of the care cascade. Median viral load was $3.14 \mathrm{log}$ higher among participants age 18-22 living with HIV than older GMSM /TP (4.44v 1.30 respectively, $\mathrm{p}=0.0022)$, reflecting both lower status awareness and care engagement in addition to higher HIV incident risk in the youngest age group. The observation that HIV prevalence was $13 \%$ among GBMSM/TP aged 18-22 years suggests that risk begins earlier in adolescence when prevention and care may be even less accessible. Although comparable evidence is scarce from elsewhere in sub Saharan Africa, Ramadhani reported higher HIV risk behaviour and incidence, yet lower healthcare engagement, status awareness and virological suppression among Nigerian GBMSM/TP aged 16-19 years. ${ }^{42}$

The WHO highlight the need for national responses to be acceptable to young key populations, ${ }^{43}$ and our findings suggest a focus on GBMSM/TP youth is overdue and will be essential to the overall success of Kenyan key population HIV response. Improving accessibility to youth may require redress of structural barriers to service access, such as age-based consent criteria, training of staff to recognise additional needs of young GBMSM/TP, but must also account for the prospect that young members 

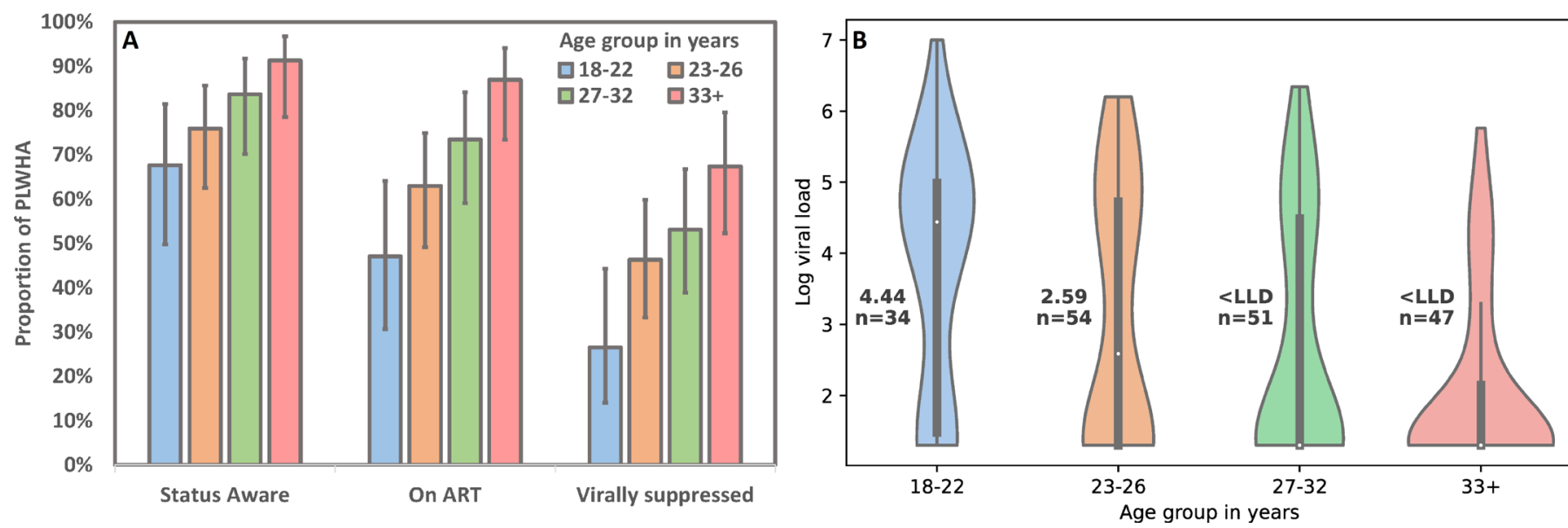

Figure 2 (A) HIV care cascade measures by age group. Point estimates are unadjusted for sampling strategy and exclude seeds. Error bars represent 95\% Cls. (B) Log viral load median and distribution by age group. Vertical bars represent IQR, white dots represent median viral load (also stated in label). <LLD: (40 copies/mm³). ART, antiretroviral therapy; LLD, lower limit of detection; PLWHA, persons living with HIV/AIDS.

of key populations will be sceptical of the confidentiality and safety of healthcare settings. ${ }^{44}$ Pettifor proposes that services for adolescent and young MSM need to be targeted and holistic, given the complex and concurrent challenges of conceptualising HIV risk and prevention during a period of personal biological and psychological change, and often alongside stressors related to acceptance and disclosure of sexual or gender identity to family and friends. ${ }^{44}$ Effective interventions targeting HIV prevention and care engagement among young MSM have mostly been tested in the USA, and offer supportive evidence for both digital interventions on testing uptake ${ }^{45}$ and peer-based network support interventions to support retention. ${ }^{46}$ Adaptation and demonstration of acceptability of interventions to young GBMSM/TP in highly stigmatised contexts should be a priority.

Our findings also suggest that improved diagnostics could complement both HIV prevention and care for GBMSM/TP in Nairobi. A small but significant proportion of GBMSM/TP were identified with prevalent acute/ early HIV infection accompanied by high viral loads, and undetected by current national testing practices. In addition, we found a high proportion of GBMSM/TP with asymptomatic, urethral and rectal STIs, well recognised as a cofactor in HIV transmission. ${ }^{47}$ Laboratory capacity for STI diagnosis remains limited and expensive in Kenya, therefore most providers, especially communitybased organisations, rely solely on syndromic management. Our findings concur with others in suggesting such approaches alone have unacceptably poor diagnostic performance. ${ }^{48} 49$ The decreasing complexity and cost of point-of-care PCR technologies should encourage policymakers to re-evaluate the cost-effectiveness of providing access to PCR-based HIV and STI diagnostics particularly in community settings. ${ }^{50}$

A key strength of the study was the population representative design that avoids many of the biases intrinsic to studies conducted solely among GBMSM/TP already engaged with research programs or service providers. RDS diagnostics suggest convergence on all main demographic measures, and these measures compared closely to a previous study of the same design in Nairobi. ${ }^{13}$ The complex steps required to demonstrate eligibility for inclusion in coupon-referral studies might have presented obstacles to legitimate study access for some genuine coupon recipients, and our inclusion criteria might also have limited participation for important subpopulations, such as persons who inject drugs or harmful alcohol users. Limitations of the study include the cross-sectional design (precluding examination of causal direction of correlates) and the reliance on self-reported measures of behaviours and service uptake that are potentially subject to memory error and social desirability bias. Foremost among these was differential under-reporting of status awareness and antiretroviral use in surveys and with care providers. This phenomenon has been reported by other population-based studies, has the potential to significantly distort interpretation of cascade measures and underscores the need for verification of self-reported measures wherever possible. ${ }^{5152}$

In summary, coverage of HIV care for GBMSM and TP living with HIV in Nairobi is close to that achieved in the general population and reflects the inclusive approach of the national HIV/AIDS strategy in Kenya. However, ending AIDS for key populations demands even better access to care, a re-energised PrEP response, and access to relevant HIV and STI diagnostics available wherever GBMSM/TP feel safe seeking these services. Going forward policy-makers must now seek to understand and address the specific sexual health service preferences of adolescent and younger key populations in order to address age-related inequalities in access to diagnosis and care.

Author affiliations

${ }^{1}$ Nuffield Department of Population Health, University of Oxford, Oxford, UK 
${ }^{2}$ Department of Social and Environmental Health Research, London School of Hygiene and Tropical Medicine, London, UK

${ }^{3}$ Partners for Health and Development, Nairobi, Kenya

${ }^{4}$ Department of Global Health \& Development, London School of Hygiene \& Tropical Medicine, London, UK

${ }^{5}$ Sigma Research, London School of Hygiene \& Tropical Medicine, London, UK

${ }^{6}$ Australian Research Centre in Sex, Health and Society, La Trobe University,

Melbourne, Victoria, Australia

${ }^{7}$ Department of Global Health \& Development, Partners for Health and Development, Nairobi, Kenya

${ }^{8}$ Department of Community Health Sciences, University of Manitoba, Winnipeg, Manitoba, Canada

\section{Twitter Peter Weatherburn @\#PeterWea}

Acknowledgements We would like to acknowledge and thank the commitment of study participants, and are grateful to our community partner organisations: the Gay and Lesbian Coalition of Kenya (GALCK); Ishtar MSM and Health Options for Young Men with AIDS (HOYMAS) for their support of study procedures and in dissemination of findings. We thank our administrative, counselling, clinical and laboratory staff at the TRANSFORM clinic and Partners for Health and Development for Africa (PHDA) for their hard work and dedication.

Contributors AS contributed to designing the study and data collection instruments, carried out quantitative analyses and wrote the first draft of the manuscript; $A B$ contributed to conceiving and designing the study and data collection instruments and drafting of the manuscript; JK and RK contributed to designing the study and data collection instruments, implementation of study procedures and commented on the manuscript. El, MK, PM, HB and CN contributed to the implementation and operation of study procedures. PW and EF contributed to conceiving and designing the study and data collection instruments and commented on the manuscript. All authors approved the final draft. JK acts as the guarantor.

Funding This work was supported by Evidence for HIV Prevention in Southern Africa (EHPSA) award number MM/EHPSA/WHC/0116029.

Competing interests None declared.

Patient consent for publication Not applicable.

Ethics approval This study was approved by the Kenya Medical Research Institute Scientific and Ethics Review Unit (KERMI/SERU/CGMR-C/CSC 044/3334), the University of Oxford, Oxford Tropical Research Ethics Committee (0xTREC 47-16) and London School of Hygiene and Tropical Medicine Human Research Ethics Committee (REF: 14144).

Provenance and peer review Not commissioned; externally peer reviewed.

Data availability statement Data are available on reasonable request. Data from this study have not been deposited publicly because of the potential risk of deductive disclosure that may arise from individual data needed for valid analysis of the data, and the potential individual and social harms that may arise from such disclosure in a context of criminalisation and stigmatisation. However, all authors aim to make the data underlying the findings of the study available for legitimate research purposes, and requests will be considered by the London School of Hygiene and Tropical Medicine Research Operations Office Data Management lead ( alex.hollander@Ishtm.ac.uk). The request must specify the purpose of research, the list of required variables, and if personally identifiers or sensitive data are sought, specify measures to maintain information security and governance that will be applied in storage, handling and reporting the data.

Supplemental material This content has been supplied by the author(s). It has not been vetted by BMJ Publishing Group Limited (BMJ) and may not have been peer-reviewed. Any opinions or recommendations discussed are solely those of the author(s) and are not endorsed by BMJ. BMJ disclaims all liability and responsibility arising from any reliance placed on the content. Where the content includes any translated material, BMJ does not warrant the accuracy and reliability of the translations (including but not limited to local regulations, clinical guidelines, terminology, drug names and drug dosages), and is not responsible for any error and/or omissions arising from translation and adaptation or otherwise.

Open access This is an open access article distributed in accordance with the Creative Commons Attribution Non Commercial (CC BY-NC 4.0) license, which permits others to distribute, remix, adapt, build upon this work non-commercially, and license their derivative works on different terms, provided the original work is properly cited, appropriate credit is given, any changes made indicated, and the use is non-commercial. See: http://creativecommons.org/licenses/by-nc/4.0/.

ORCID iD

Adrian D Smith http://orcid.org/0000-0003-0036-1490

\section{REFERENCES}

1 Beyrer C, Baral SD, van Griensven F, et al. Global epidemiology of HIV infection in men who have sex with men. Lancet 2012;380:367-77.

2 Baral SD, Poteat T, Strömdahl S, et al. Worldwide burden of HIV in transgender women: a systematic review and meta-analysis. Lancet Infect Dis 2013;13:214-22.

3 Poteat T, Scheim A, Xavier J, et al. Global epidemiology of HIV infection and related syndemics affecting transgender people. $J$ Acquir Immune Defic Syndr 2016;72:S210-9.

4 Poteat T, Ackerman B, Diouf D, et al. HIV prevalence and behavioral and psychosocial factors among transgender women and cisgender men who have sex with men in 8 African countries: a cross-sectional analysis. PLoS Med 2017;14:e1002422.

5 Smith AD, Tapsoba P, Peshu N, et al. Men who have sex with men and HIV/AIDS in sub-Saharan Africa. Lancet 2009;374:416-22.

6 Pew Research Center. The global divide on homosexuality persists. Pew Research Center, 2020.

7 UNAIDS. The gap report. Geneva: UNAIDS, 2014.

8 Risher K, Mayer KH, Beyrer C. HIV treatment cascade in MSM, people who inject drugs, and sex workers. Curr Opin HIV AIDS 2015;10:420-9.

9 Stannah J, Dale E, Elmes J. Sub-optimal engagement of African MSM in the HIV treatment cascade: a systematic review and metaanalysis HIV R4P. Madrid, Spain 2018.

10 Gupta S, Granich R. National HIV care continua for key populations. $J$ Int Assoc Provid AIDS Care 2017;16:125-32.

11 Mwau M, Syeunda CA, Adhiambo M, et al. Scale-up of Kenya's national HIV viral load program: findings and lessons learned. PLOS One 2018;13:e0190659.

12 National AIDS and STI Control Programme. KENPHIA 2018 preliminary report. Nairobi: NASCOP, 2020.

13 Muraguri N, Tun W, Okal J, et al. HIV and STI prevalence and risk factors among male sex workers and other men who have sex with men in Nairobi, Kenya. J Acquir Immune Defic Syndr 2015;68:91-6.

14 Kunzweiler CP, Bailey RC, Mehta SD, et al. Factors associated with viral suppression among HIV-positive Kenyan gay and bisexual men who have sex with men. AIDS Care 2018;30:S76-88.

15 Ministry of Health, National AIDS and STI Control Programme. Guidelines on the use of anti-retroviral drugs for treating and preventing HIV infection in Kenya. Nairobi, Kenya: Ministry of Health, 2016.

16 WHO. Consolidated Guidlines on HIV prevention, diagnosis, treatment and care for key populations: 2016 update. Geneva, Switzerland: WHO, 2016.

17 Heckathorn DD. Respondent-driven sampling: a new approach to the study of hidden populations. Soc Probl 1997;44:174-99.

18 Lyons C, Stahlman S, Holland C, et al. Stigma and outness about sexual behaviors among cisgender men who have sex with men and transgender women in Eswatini: a latent class analysis. BMC Infect Dis 2019;19:211.

19 Stahlman S, Hargreaves JR, Sprague L, et al. Measuring sexual behavior stigma to inform effective HIV prevention and treatment programs for key populations. JMIR Public Health Surveill 2017;3:e23.

20 Babor T, Higgins-Biddle J, Saunders J. AUDIT: the alcohol use disorders identification test. In: Guidlines for use in primary care. 2nd edn. Geneva: WHO, 2001.

21 National AIDS and STI Control Programme. Guidelines for HIV testing services in Kenya. Nairobi, Kenya: Government of Kenya, 2015.

22 Centers for Disease Control. Understanding the HIV care continuum. Atlanta, Georgia: Division of HIV/AIDS Preventon, National Center for HIV/AIDS, Viral Hepatitis, STD, and TB Prevention, CDC, 2017.

23 Handcock MS, Fellows IE, Gile KJ. RDS: respondent-driven sampling, 2012. Available: https://CRAN.R-project.org/package=RDS [Accessed 30 Oct 2020].

24 Gile KJ, Johnston LG, Salganik MJ. Diagnostics for respondentdriven sampling. J R Stat Soc Ser A Stat Soc 2015;178:241-69.

25 Volz E, Heckathorn DD. Probability based estimation theory for respondent driven sampling. J Offic Stat 2008;24:79-97.

26 Smith AD, Kimani J, Kabuti R, et al. HIV burden and correlates of infection among transfeminine people and cisgender men who have 
sex with men in Nairobi, Kenya: an observational study. Lancet HIV 2021;8:e274-83.

27 Huber PJ. The behvior of maximum likelihood estimates under nonstandard conditions. Berkeley, CA: University of California Press, 1967.

28 Barros AJD, Hirakata VN. Alternatives for logistic regression in crosssectional studies: an empirical comparison of models that directly estimate the prevalence ratio. BMC Med Res Methodol 2003;3:21.

29 Avery L, Rotondi N, McKnight C, et al. Unweighted regression models perform better than weighted regression techniques for respondent-driven sampling data: results from a simulation study. BMC Med Res Methodol 2019;19:202.

30 Singh K, Brodish P, Mbai F, et al. A venue-based approach to reaching MSM, IDUs and the general population with VCT: a three study site in Kenya. AIDS Behav 2012;16:818-28.

31 Sandfort TGM, Dominguez K, Kayange N, et al. HIV testing and the HIV care continuum among sub-Saharan African men who have sex with men and transgender women screened for participation in HPTN 075. PLoS One 2019;14:e0217501.

32 Smith AD, Muhaari AD, Agwanda C, et al. Heterosexual behaviours among men who sell sex to men in coastal Kenya. AIDS 2015;29:S201-10.

33 Were D, Musau A, Mutegi J, et al. Using a HIV prevention cascade for identifying missed opportunities in PrEP delivery in Kenya: results from a programmatic surveillance study. J Int AIDS Soc 2020;23:e25537.

34 Ayala G, Makofane K, Santos G-M. Hiv treatment cascades that leak correlates of drop-off from the HIV care continuum among men who have sex with men worldwide. J AIDS Clin Res 2014;05.

35 O'Halloran C, Sun S, Nash S. HIV in the United Kingdom: towards zero 2030. London: Public Health England, 2019.

36 Muessig KE, LeGrand S, Horvath KJ, et al. Recent mobile health interventions to support medication adherence among HIV-positive MSM. Curr Opin HIV AIDS 2017;12:432-41.

37 Nelson KM, Perry NS, Horvath KJ, et al. A systematic review of mHealth interventions for HIV prevention and treatment among gay, bisexual, and other men who have sex with men. Trans/ Behav Med 2020;10:1211-20.

38 Cao B, Gupta S, Wang J, et al. Social media interventions to promote HIV testing, linkage, adherence, and retention: systematic review and meta-analysis. J Med Internet Res 2017;19:e394.

39 Fearon E, Bourne A, Tenza S, et al. Online socializing among men who have sex with men and transgender people in Nairobi and Johannesburg and implications for public health-related research and health promotion: an analysis of qualitative and respondentdriven sampling survey data. J Int AIDS Soc 2020;23:e25603.

40 LINKAGES. Peer navigation for key populations: implementation guide: FHI 360. LINKAGES, 2017.
41 Graham SM, Micheni M, Chirro O, et al. A randomized controlled trial of the Shikamana intervention to promote antiretroviral therapy adherence among gay, bisexual, and other men who have sex with men in Kenya: feasibility, acceptability, safety and initial effect size. AIDS Behav 2020;24:2206-19.

42 Ramadhani HO, Crowell TA, Nowak RG, et al. Association of age with healthcare needs and engagement among Nigerian men who have sex with men and transgender women: cross-sectional and longitudinal analyses from an observational cohort. J Int AIDS Soc 2020;23:e25599.

43 Baggaley R, Armstrong A, Dodd Z, et al. Young key populations and HIV: a special emphasis and consideration in the new who consolidated guidelines on HIV prevention, diagnosis, treatment and care for key populations. J Int AIDS Soc 2015;18:19438.

44 Pettifor A, Stoner M, Pike C, et al. Adolescent lives matter: preventing HIV in adolescents. Curr Opin HIV AIDS 2018;13:265-73.

45 Bauermeister JA, Pingel ES, Jadwin-Cakmak L, et al. Acceptability and preliminary efficacy of a tailored online HIV/STI testing intervention for young men who have sex with men: the get connected! program. AIDS Behav 2015;19:1860-74.

46 Bouris A, Jaffe K, Eavou R, et al. Project nGage: results of a randomized controlled trial of a Dyadic network support intervention to retain young black men who have sex with men in HIV care. AIDS Behav 2017;21:3618-29.

47 Bernstein KT, Marcus JL, Nieri G, et al. Rectal gonorrhea and chlamydia reinfection is associated with increased risk of HIV seroconversion. J Acquir Immune Defic Syndr 2010;53:537-43.

48 Sanders EJ, Thiong'o AN, Okuku HS, et al. High prevalence of Chlamydia trachomatis and Neisseria gonorrhoeae infections among HIV-1 negative men who have sex with men in coastal Kenya. Sex Transm Infect 2010;86:440-1.

49 Shah NS, Kim E, de Maria Hernández Ayala F, et al. Performance and comparison of self-reported STI symptoms among high-risk populations - MSM, sex workers, persons living with HIV/AIDS - in El Salvador. Int J STD AIDS 2014;25:984-91.

50 Palmer S, Dijkstra M, Ket JC, et al. Acute and early HIV infection screening among men who have sex with men, a systematic review and meta-analysis. J Int AIDS Soc 2020;23:e25590.

51 Fogel JM, Sandfort T, Zhang Y, et al. Accuracy of self-reported HIV status among African men and transgender women who have sex with men who were screened for participation in a research study: HPTN 075. AIDS Behav 2019;23:289-94.

52 Mooney AC, Campbell CK, Ratlhagana M-J, et al. Beyond social desirability bias: investigating inconsistencies in self-reported HIV testing and treatment behaviors among HIV-positive adults in North West Province, South Africa. AIDS Behav 2018;22:2368-79. 